this subject, has written: "I remember clearly lying awake on the third night of a disaster and feeling inside me the overwhelming load of grief that was ahead for those people and families we had met at the morgue. . . I felt a terrible sadness and a sense of loss as well as a great burden." 3

Student nurses and medical students generally receive little training on dealing with death and dying, ${ }^{7}$ and there is rarely time to visit a mortuary. Social workers, clinical psychologists, and counsellors who may be asked to provide psychological help after a tragedy have usually also had little training for such a task. Training should be improved, but it will never be a substitute for strong support from senior staff.

Relatives should thus, it seems, be encouraged to view bodies, and photographs should be kept. But much more research is needed, and reluctance by relatives to see a body should always be respected.

Principal Clinical Psychologist,

FIONA CATHCART

Gogarburn Hospital, Edinburgh EH12 9BJ

1 Lewis E. Management of stillbirth. Coping with an unreality. Lancet 1976;ii:619-20.

2 Savage W. Perinatal loss and the medical team. Midwife, Health Visitor and Community Nurse 1978; September 292-5.

3 Raphael B. When disaster strikes. New York: Basic Books, 1986.

4 Singh B, Raphael B. Postdisaster morbidity of the bereaved. A possible role for preventive psychiatry. I Nerv Ment Dis 1981;169:203-12.

Hingley P, Cooper C. Stress and the nurse manager. Chichester: Wiley, 1986

6 Jones DR. Secondary disaster victims. The emotional effects of recovering and identifying human remains. Am $\mathcal{f}$ Psychiatry 1985;142:303-7.

Irwin WG. Teaching terminal care at Queen's University, Belfast. Br Med f 1984;ii:1509-11.

\title{
Ribavirin and acute bronchiolitis in infancy
}

\author{
Not needed for those who were previously well
}

Acute bronchiolitis is by far the commonest lower respiratory tract infection of infancy. During the winter epidemic up to $2 \%$ of the children born in the previous 12 months will require inpatient care for this condition. Although the babies often seem to be distressed in the short term, the mortality is low-less than $1 \%$ of those admitted to hospital who were previously healthy. Mortality as high as a third has, however, been reported in those with pre-existing cardiopulmonary disease - for example, bronchopulmonary dysplasia or severe congenital heart disease. ${ }^{1}$ In addition, in the three years after the acute attack, four fifths of those admitted to hospital will have attacks of coughing and wheezing, ${ }^{2}$ and even after 10 years the prevalence of asthmatic symptoms and abnormal airway liability will be twice that of controls matched for age. ${ }^{3}$ Clinical trials have not shown any benefit from treatments ( $\beta_{2}$ stimulants, anticholinergics, and systemic steroids) that might reduce the obstruction of small airways in the acute phase of the illness. ${ }^{+6}$ The development of a drug, ribavirin, that is effective in vitro against the respiratory syncytial virus, the agent responsible for most cases, was thus welcomed with excitement. This initial response is currently being reassessed.

Ribavirin, which closely resembles guanosine and inosine, is given as an aerosol mist. The manufacturers have provided a mist generator that produces particles with a mean diameter of about $1.3 \mu \mathrm{m}$. The extent to which these particles penetrate the small airways of infants with acute bronchiolitis is unknown, and we are almost equally ignorant about the optimal period of treatment. The manufacturers recommend that treatment is given for about 20 hours a day, but the only clinical data to support this are in a single study in which treatment was given for only 12 hours.' This produced less satisfactory results than other studies in which treatment was given for about 20 hours. Currently the mist is delivered into a headbox in those who are breathing spontaneously. For babies requiring ventilatory support the output of the particle generator may be fed into the ventilator circuit. ${ }^{8}$ To what extent this modifies the size of the particles is not known, but the ventilator circuits have needed modification to prevent malfunction of the expiratory valve because of a build up of ribavirin.

No adverse side effects have been reported, but ribavirin has been shown to be teratogenic in pregnant rodents when given orally. ${ }^{9}$ Tests on nurses who have been caring for children being treated with ribavirin have, however, failed to show any of the drug in the blood or urine, making it extremely unlikely that hospital staff or visitors in the early stage of pregnancy are at risk. One problem with ribavirin is its cost $-£ 500$ for a five day course. Because of this high cost we must look closely at the evidence of efficacy.

Four published "double blind" clinical trials have examined the effects of ribavirin or placebo on children with acute bronchiolitis who had previously been well..$^{70-12}$ All found that clinical condition assessed either by scores of severity or cardiorespiratory measurements tended to improve more rapidly in those having treatment, with differences apparent within $24-48$ hours. There was a significant improvement in oxygen saturation or transcutaneous oxygen tension in two studies in which this was recorded. ${ }^{10} 12$ There was, however, no evidence that the time to discharge was reduced; patterns of viral excretion were unaltered in three of the studies ${ }^{7112}$; and, as expected, none of the children died. Furthermore, the methods of selecting patients and the techniques used to assess the severity of symptoms in three of the four studies have been criticised. ${ }^{13}$

Two studies have examined infants with pre-existing cardiorespiratory disease. In one study 26 babies, most of whom had bronchopulmonary dysplasia, showed an improvement in scores for symptoms within 24 hours and an improvement in arterial oxygen pressure of $21.5 \mathrm{~mm} \mathrm{Hg}$ compared with $1.4 \mathrm{~mm} \mathrm{Hg}$ among patients taking placebo. ${ }^{14}$ Again, none of the babies died. The remaining study by Conrad et al was not randomised but compared 33 patients with either severe illness or pre-existing cardiorespiratory disease who were treated with 97 patients admitted during the same epidemic but not treated. ${ }^{15}$ The authors claimed that ribavirin was associated with a more rapid resolution of symptoms, but as the groups were so different interpretation is difficult.

At the moment there seems little to justify using ribavirin in previously healthy babies admitted to hospital with bronchiolitis caused by respiratory syncytial virus. This advice might have to be changed, however, if treatment in the acute phase is shown to reduce dramatically long term morbidity, and studies are now in hand to assess this. Although there is no conclusive evidence that ribavirin saves lives in those with pre-existing cardiopulmonary disease, these babies are at considerable risk: a reasonable case may thus be made for 
giving ribavirin, which seems to speed recovery in those who are critically ill or needing ventilatory support.

Professor of Paediatric Respiratory Medicine,

A D MILNER

University Hospital,

Nottingham NG7 2UH

Macdónald NE, Hal CB, Suffin SC, Alexson C, Harris PJ, Manning JA. Respiratory syncytial virus infection in infants with congenital heart disease. N Engl J Med 1982;307:397-400.

Webb MSC, Henry RL, Milner AD, Stokes GM, Swarbrick AS. Continuing respiratory problems three and a half years after acute viral bronchiolitis. Arch Dis Child 1985;60:1064-7.

3 Pullan CR, Hey EN. Wheezing, asthma, and pulmonary dysfunction 10 years after infection with respiratory syncytial virus in infancy. Br Med f 1982;284:1665-9.

4 Lenney W, Milner AD. Alpha and beta adrenergic stimulants in bronchiolitis and wheezy bronchitis in children under 18 months of age. Arch Dis Child 1978;53:707-9.

5 Henry R, Milner AD, Stokes GM. Ineffectiveness of ipratropium bromide in acute bronchiolitis. A short report. Arch Dis Child 1983;58:925-6.
6 Connolly JH, Field CMB, Glasgow JFT, Slattery CM, MacLynn DM. A double-blind trial of prednisolone in epidemic bronchiolitis due to respiratory syncytial virus. Acta Paeder Scand 1969;58:116-9.

Taber LH, Knight V, Gilbert BE, et al. Ribavirin aerosol treatment of bronchiolitis associated with respiratory syncytial virus infection in infants. Pediatrics 1983;72:613-8.

8 Outwater KM, Meissner HC, Peterson MB. Ribavirin administered to infants receiving mechanical ventilation. Am $\mathcal{F}$ Dis Child 1988;142:512-5.

Committee on Infectious Diseases. Ribavirin therapy of respiratory syncytial virus. Pediatrics 1987;79:475-6.

10 Hall CB, McBride JT, Walsh EE, et al. Aerosolized ribavirin treatment of infants with respiratory syncytial infection. A randomized double-blind study. N Engl $\}$ Med 1983;308:1443-7.

11 Barry W, Cockburn F, Cornall R, Price JF, Sutherland G, Vardag A. Ribavirin aerosol for acute bronchiolitis. Arch Dis Child 1986;61:593-7.

12 Rodriguez WJ, Kim HW, Brandt CD. Aerosolized ribavirin in the treatment of patients with respiratory syncytial virus disease. Pediatr Infect Dis $\mathcal{f}$ 1987;6:159-63.

13 Wald ER, Dashefsky B, Green M. In re ribavirin: A case of premature adjudication? I Pediat 1988;112:154-8.

14 Hall CB, McBride JT, Gala CL, et al. Ribavirin treatment of respiratory syncytial viral infection in infants with underlying cardiopulmonary disease. $\mathcal{F} A M A$ 1985;254:3047-51.

15 Conrad DA, Christenson JC, Waner JL, et al. Aerosolized ribavirin treatment of respiratory syncytial virus infection in infants hospitalized during an epidemic. Pediatr Infect Dis 1987;6:152-8.

\title{
Flumazenil: a benzodiazepine antagonist
}

\author{
Many uses, possibly including withdrawal from benzodiazepines
}

Flumazenil is a benzodiazepine antagonist that is already used to reverse sedation induced by benzodiazepine drugs. It may also prove useful in helping patients withdraw from benzodiazepines.

It was characterised in $1981^{1}$ and reverses all the effects of benzodiazepines without changing their bioavailability or kinetics. ${ }^{2}$ It has minimal effects on the normal central nervous system. ${ }^{3}$ Incremental doses up to $0 \cdot 5-1 \cdot 0 \mathrm{mg}$ intravenously are effective,,$^{+7}$ and doses of $600 \mathrm{mg}$ orally ${ }^{8}$ and $100 \mathrm{mg}$ intravenously ${ }^{23}$ are well tolerated in normal volunteers. When taken by mouth flumazenil is rapidly absorbed and has a high hepatic clearance. ${ }^{9}$ Its plasma clearance is 691 (SD 216) $\mathrm{ml} / \mathrm{min}$, and its half life is 54 (12) minutes. Only $40 \%$ is bound to plasma proteins, ${ }^{9}$ and it rapidly enters and subsequently clears the central nervous system. ${ }^{1011}$ Less than $0 \cdot 2 \%$ is excreted unchanged. Its duration of action after a single intravenous injection has varied from 15 to 140 minutes, depending on the dose. ${ }^{12-14}$ Feelings of anxiety occasionally occur during reversal of sedation with benzodiazepines, ${ }^{4}$ and the dose of flumazenil should always be titrated slowly to a desired state. Resedation has also been reported in patients whose sedation with benzodiazepines has been reversed one to two hours after the flumazenil.

There is concern that flumazenil might precipitate an acute withdrawal syndrome in patients who have been taking benzodiazepines for a long time ${ }^{15}$ and withdrawal symptoms, although never prolonged or severe, have followed treatment with flumazenil in several species of animal. ${ }^{16}$ Both endogenous and exogenous ligands are antagonised by flumazenil, and hence the drug should not cause adverse reactions in patients who have been treated clinically if they have built up concentrations of inverse agonists. ${ }^{17}$ It seems likely that dependence on benzodiazepines is associated with an allosteric change in the benzodiazepine receptor, ${ }^{18} 19$ augmenting the action of inverse agonists,,$^{20}$ and that flumazenil resets the receptors for normal function. It may thus help in managing withdrawal from benzodiazepines, ${ }^{21}$ although clinical trials are required to resolve this controversy. Flumazenil has, however, caused convulsions in a patient with epilepsy who was receiving several drugs, ${ }^{22}$ and it should be given circumspectly if there is any doubt about whether a patient with a benzodiazepine overdose may also have taken a potentially convulsant drug.

In patients with a benzodiazepine overdose flumazenil provides an opportunity for neurological assessment by temporarily reversing sedation, but as mortality is low prolonged administration of the drug may not be justified. It may, however, prevent the need for intubation and artificial ventilation, particularly when the patient is being transported and during procedures such as gastric lavage. In patients with raised intracranial pressure after head injury flumazenil may reverse the protective effect of benzodiazepine treatment. ${ }^{23}$

Flumazenil has also been used to reverse paradoxical reactions to benzodiazepines, ${ }^{5}$ in hepatic encephalopathy, ${ }^{24}$ alcohol intoxication, ${ }^{25}$ and coma caused by selective degeneration of the thalamic nuclei ${ }^{26}$ and to help weaning patients from ventilators. ${ }^{27}$ In endoscopy clinics where benzodiazepine sedation is used but patients are kept conscious flumazenil allows immediate reduction of sedation if verbal contact is lost or apnoea occurs. To minimise the risk of resedation long acting benzodiazepines should be avoided, and midazolam is better. Flumazenil has been used to reverse anaesthesia supplemented by midazolam. ${ }^{7}$

Director and Professor of Anaesthetics,

JAMES G WHITWAM

Royal Postgraduate Medical School,

London W12 0NN

1 Hunkeler W, Mohler H, Pieri L, et al. Selective antagonists of benzodiazepines. Nature 1981;290:514-6.

O'Boyle C, Lambe R, Darragh A, Taffe W, Brick I, Kenny M. Rol5-1788 antagonises the effects of diazepam in man without affecting its bioavailability. Br f Anaesth 1983;55:349-55.

3 Darragh A, Lambe $R$, Kenny M, Brick I. Tolerance of healthy volunteers to intravenous administration of the benzodiazepine antagonist Rol5-1788. Eur f Clin Pharmacol 1983;24: 569-70.

4 Kirkegaard L, Knudsen L, Jensen S, Kruse A. Benzodiazepine antagonist Ro15-1788. Antagonism of diazepam sedation in outpatients undergoing gastroscopy. Anaesthesia 1986;41:1184-8.

Ricou R, Forster A, Bruckner A, Chastonay P, Gemperle M. Clinical evaluation of a specific benzodiazepine antagonist (Rol5-1788). Studies in elderly patients after regional anaesthesia under benzodiazepine sedation. $\mathrm{Br} \mathcal{F}$ Anaesth 1986;58:1005-11.

6 Sage DJ, Close A, Boas RA. Reversal of midazolam sedation with Anexate. Br $\mathcal{J}$ Anaesth 1987;59:459-64

Alon E, Baitella L, Hossli G. Double-blind study of the reversal of midazolam-supplemented general anaesthesia with Rol5-1788. Br $\mathcal{f}$ Anaesth 1987;59:455-8.

8 Darragh A, Lambe R, Kenny M, Brick I, O’Boyle C, Taffe W. Rol5-1788 antagonises the central diazepam in man without altering diazepam availability. Br $\mathcal{F}$ Clin Pharmacol 1982;14:666-82.

Klotz U, Kanto J. Pharmacokinetics and clinical use of flumazenil (Ro15-1788). Clin Pharmacokinet 1988;14:1-12.

10 Shinotoh $\mathrm{H}$, Yamasaki $\mathrm{T}$, Inoue $\mathrm{O}$, et al. Visualisation of specific binding sites of benzodiazepines in human brain. $\mathcal{F}$ Nucl Med 1986;27:1593-9.

11 Samson Y, Hantraye P, Baron JC, Soussaline F, Comar D, Mazière M. Kinetics and displacement of ["C] Ro15-1788, a benzodiazepine antagonist, studied in human brain in vivo by positron tomography. Eur F Pharmacol 1985;110:247-51.

12 Klotz U, Ziegler G, Reimann IW. Pharmacokinetics of the selective benzodiazepine antagonis Rol5-1788 in man. Eur $\mathcal{F}$ Pharmacol 1984;27:115-7.

13 Lauven PM, Schwilden H, Stoeckel H, Greenblatt DJ. The effect of a benzodiazepine antagonis Rol5-1788 in the presence of stable concentrations of midazolam. Anesthesiology 1985;63:61-4.

14 Klotz U, Reimann IW, Ziegler G, Ludwig L. Pharmacodynamic interaction between midazolam and a specific benzodiazepine antagonist in humans. $\mathcal{F}$ Clin Pharmacol 1985;25:400-6. 